\title{
ChemComm
}

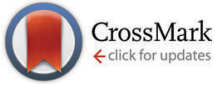

Cite this: Chem. Commun., 2015, 51, 6773

Received 6th February 2015 Accepted 9th March 2015

DOI: $10.1039 / \mathrm{c} 5 \mathrm{cc} 01123 \mathrm{j}$

www.rsc.org/chemcomm

\section{Simple coordination complex-derived three-dimensional mesoporous graphene as an efficient bifunctional oxygen electrocatalyst $\dagger$}

\author{
Kyung Joo Lee, ${ }^{a}$ Young Jin Sa, ${ }^{a}$ Hu Young Jeong, ${ }^{\text {b }}$ Christopher W. Bielawski, ${ }^{\text {ac }}$ \\ Sang Hoon Joo ad and Hoi Ri Moon*a
}

\begin{abstract}
3D mesoporous graphene (mesoG) was synthesized from [ $\left.\mathrm{Ni}_{2}(\mathrm{EDTA})\right]$ (EDTA = ethylenediaminetetraacetate). The material is comprised of interconnected $4 \mathrm{~nm}$-sized hollow carbon shells composed of 3-4 layers of graphene and exhibits high bifunctional electrocatalytic activity as well as high durability for use in oxygen evolution and reduction reactions.
\end{abstract}

Due to their numerous potential applications in gas adsorption, ${ }^{1}$ energy storage, ${ }^{2}$ and catalysis, ${ }^{3}$ porous carbon materials have attracted tremendous interest. In particular, given the high porosity of carbon-based graphitic frameworks, such materials are expected to exhibit excellent electrochemical and mechanical properties ${ }^{4,5}$ as well as high thermal conductivity. ${ }^{6}$ Of the several forms of graphitic porous carbons, 3D porous graphene-like materials are attractive because they are expected to display high conductivities and large surface areas. While ideal graphene is composed of a single layer of $\mathrm{sp}^{2}$ hybridized carbon atoms with a high theoretical surface area $\left(2630 \mathrm{~m}^{2} \mathrm{~g}^{-1}\right)$, its strong stacking affinity via the formation of $\pi-\pi$ interactions can hamper the full utilization of its intrinsic properties in practical applications. ${ }^{4,7}$ To integrate the functionality of graphene with structural features that prevent undesired stacking, efforts have been directed toward the synthesis of 3D porous graphene-like networks. For instance, Chen et al. reported the synthesis of graphene foams via a template-directed chemical vapor deposition (CVD) that utilized nickel foam both as a template and as a catalyst. ${ }^{8}$ Similarly, $3 \mathrm{D}$ porous graphene networks have been prepared by CVD in the presence of templates such as 3D assembled colloidal silica ${ }^{9}$ and porous $\mathrm{MgO}^{10}$ along with additional catalysts to facilitate graphitization. However, such template-assisted CVD methods are

\footnotetext{
${ }^{a}$ Department of Chemistry, Ulsan National Institute of Science and Technology (UNIST), UNIST-gil 50, Ulsan 689-798, Republic of Korea.

E-mail: hoirimoon@unist.ac.kr

${ }^{b}$ UNIST Central Research Facilities (UCRF), Ulsan National Institute of Science and Technology (UNIST), UNIST-gil 50, Ulsan 689-798, Republic of Korea

${ }^{c}$ Center for Multidimensional Carbon Materials, Institute for Basic Science (IBS), Ulsan 689-798, Republic of Korea

${ }^{d}$ School of Energy and Chemical Engineering, Ulsan National Institute of Science and Technology (UNIST), UNIST-gil 50, Ulsan 689-798, Republic of Korea

$\dagger$ Electronic supplementary information (ESI) available. See DOI: 10.1039/c5cc01123j
}

commonly unsuitable for large-scale syntheses and often require templates. An alternative approach is the assembly of materials which are related graphene, such as graphene oxide (GO) and reduced graphene oxide (rGO), followed by activation. ${ }^{11}$ Despite the potential advantage of mass production, such a method might yield lower electrochemical performances caused by damage of the GO and rGO surfaces. Another method is the hybridization of graphene with organic or inorganic materials that effectively function as 'spacers' between the graphene layers. ${ }^{12,13}$ However, this approach is susceptible to the restacking of $2 \mathrm{D}$ graphene layers due to low pillar densities as compared to the overall surface area. ${ }^{13}$

Herein, we report that the direct thermal conversion of a $\mathrm{Ni}^{\mathrm{II}}$ coordination complex followed by etching can yield 3D mesoporous graphene (mesoG). The method is cost effective, may be performed on the gram scale, and can proceed without the aid of additional templates, catalysts or CVD techniques (Scheme 1). During the thermal conversion of the $\mathrm{Ni}^{\mathrm{II}}$ complex under an inert atmosphere, the $\mathrm{Ni}^{\mathrm{II}}$ ionic centers are transformed in situ into $4 \mathrm{~nm}$-sized Ni NPs (Fig. 1a), which act as catalysts that facilitate the graphitization of amorphous carbon from the organic ligands while also serving as a template for the creation of mesopores. The resulting $3 \mathrm{D}$ mesoG material is composed of a 3D interconnected structure of hollow carbon shells comprised of 3-4 graphene layers. In addition, the material features small,
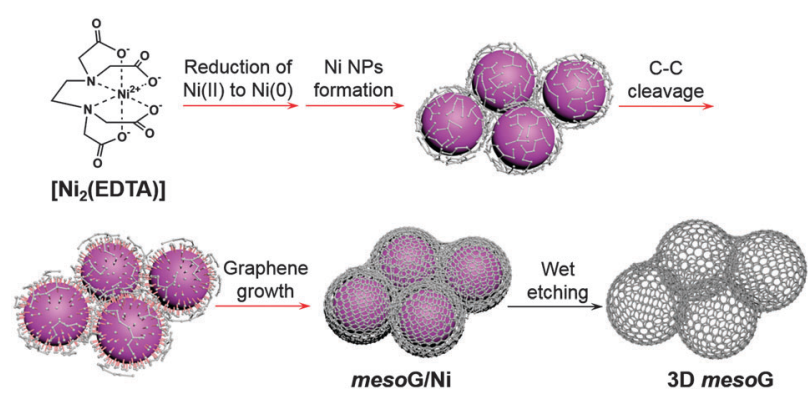

Scheme 1 Schematic representation of the thermal conversion of [ $\left.\mathrm{Ni}_{2}(\mathrm{EDTA})\right]$ into three-dimensional mesoporous graphene, 3D mesoG. The processes indicated by the red arrows occurred during the one-step heat treatment of $\left[\mathrm{Ni}_{2}(\mathrm{EDTA})\right]$. 

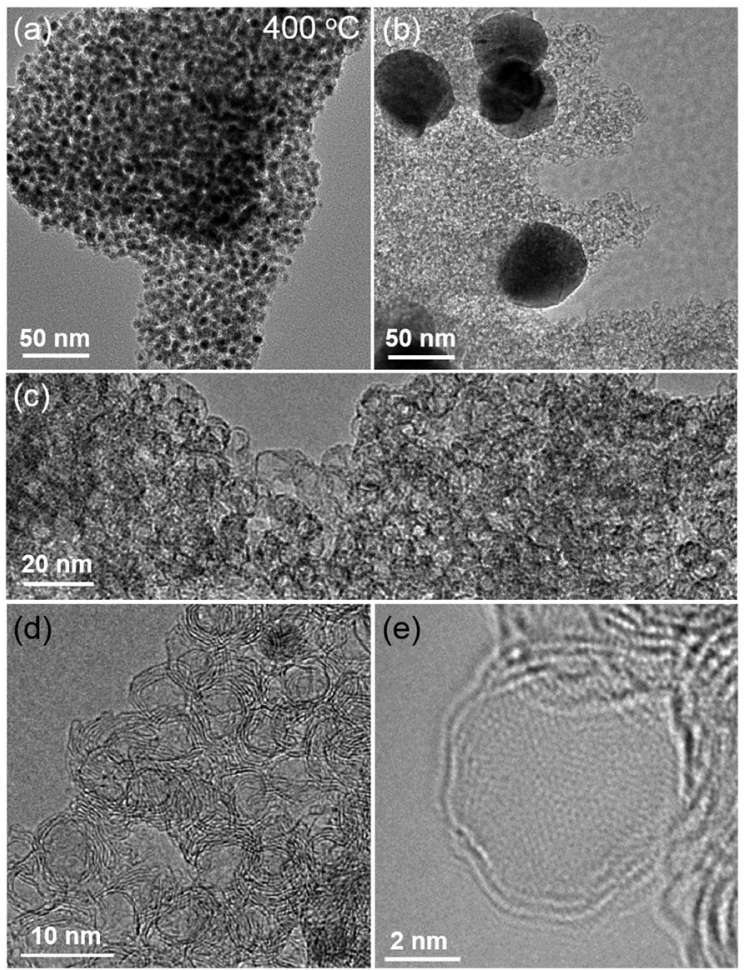

Fig. 1 TEM image of (a) mesoG/Ni during the thermal conversion at $400{ }^{\circ} \mathrm{C}$, and (b) mesoG/Ni after heat treatment at $1000{ }^{\circ} \mathrm{C}$, and (c-e) 3D mesoG at various magnifications.

uniform mesopores ( $\sim 4 \mathrm{~nm}$ in diameter), a large surface area, and a high $\mathrm{C} / \mathrm{O}$ ratio. The $3 \mathrm{D}$ mesoG also exhibits high activity and durability as a bifunctional electrocatalyst for oxygen reduction and evolution reactions (ORR and OER, respectively), revealing its promise as a non-precious metal electrocatalyst for use in energy conversion and storage devices. ${ }^{14}$

The $\mathrm{Ni}^{\mathrm{II}}$ coordination complex used herein can be readily prepared via the coordination of $\mathrm{Ni}^{\mathrm{II}}$ ions with ethylenediaminetetraacetic acid ( $\mathrm{H}_{4}$ EDTA) in the presence of $N, N, N$-triethylamine (TEA), which serves to deprotonate the carboxylic acid. In the corresponding product, $\left[\mathrm{Ni}_{2}\right.$ (EDTA) $],{ }^{15}$ which is a blue powder, the $\mathrm{Ni}^{\mathrm{II}}$ center is chelated by an EDTA ligand to form six coordination bonds with four oxygen atoms of the carboxylates and two nitrogen atoms of the tertiary amines.

With $\left[\mathrm{Ni}_{2}\right.$ (EDTA)] in hand, $1.15 \mathrm{~g}$ of the complex was heated to $1000{ }^{\circ} \mathrm{C}$ at a ramp rate of $10{ }^{\circ} \mathrm{C} \mathrm{min}^{-1}$ under a nitrogen flow of $500 \mathrm{~mL} \mathrm{~min}^{-1}$. After maintaining the temperature of the reaction at $1000{ }^{\circ} \mathrm{C}$ for $1 \mathrm{~h}$, the solid was cooled to room temperature, which resulted in the formation of $0.32 \mathrm{~g}$ of a black powder. Elemental composition analysis of the resulting powder revealed that during the thermolysis of [ $\left.\mathrm{Ni}_{2}(\mathrm{EDTA})\right]$, most of the $\mathrm{H}, \mathrm{N}$, and $\mathrm{O}$ were removed, while the $\mathrm{Ni}$ and $30 \%$ of the $\mathrm{C}$ contents remained (mesoG/Ni, Table S1 and Fig. S2, ESI $\dagger$ ). Transmission electron microscopy (TEM) (Fig. 1b) revealed that after the thermal treatment, the black powder was composed of $3 \mathrm{D}$ carbon materials and $\sim 50 \mathrm{~nm}$-sized Ni NPs (mesoG/Ni). The Ni NPs could be removed by a wet etching process to obtain a relatively metal-free carbon material $(\sim 0.1 \mathrm{~g})$ where approximately $1 \mathrm{wt} \%$ of the $\mathrm{Ni}$ remained in the 3D mesoG after etching, as determined by thermogravimetric analysis (TGA) under oxygen (Table S1 and Fig. S3, ESI $\dagger$ ). Interestingly, the 3D mesoG also contained $1.7 \mathrm{wt} \%$ of nitrogen, presumably from the EDTA ligands, and thus can be considered an N-doped carbon. Fig. 1c and d show that the obtained carbon materials consisted of small hollow carbon shells in addition to large shells. A closer observation (Fig. 1e) via atomic resolution TEM (AR-TEM) revealed that these small hollow carbon shells were composed of 3-4 layers of graphene with an inner diameter of $\sim 4 \mathrm{~nm}$, and were interconnected to produce the 3D nanostructured mesoG. We note that even after etching the Ni NPs from hollow carbon, the 3D mesoG structure did not collapse. Furthermore, elemental composition analysis of the 3D mesoG (Table S1, ESI $\dagger$ ) revealed that etching with a strong acid had a negligible effect on the chemical state of the 3D mesoG. Scanning electron microscopy (SEM) analysis of the 3D mesoG revealed the external microscopic morphology of the integrated graphene shells (see Fig. S4, ESI $\dagger$ for an image of this material). Notably, the synthetic method can be scaled and at least tens of grams of the $\left[\mathrm{Ni}_{2}\right.$ (EDTA)] precursor may be used.

To identify the origin of the formation of the hollow shell and the 3D graphene-like structure, variable temperature X-ray powder diffraction (VT-XRPD) experiments were performed during the treatment of $\left[\mathrm{Ni}_{2}\right.$ (EDTA)] (Fig. S5a, ESI $\dagger$ ). When the temperature reached $400{ }^{\circ} \mathrm{C}$, a broad signal near $2 \theta=45^{\circ}$ was detected. Upon further increase of the temperature, the peak at $45^{\circ}$ became sharper and was accompanied by the formation of two newly evolved peaks at $52^{\circ}$ and $76^{\circ}$, which were characteristic reflections of a cubic $\mathrm{Ni}^{0}$ structure (JCPDS file no. 04-0850). When the temperature was further increased to $1000{ }^{\circ} \mathrm{C}$, a very small but clear peak at $26^{\circ}$ was observed and a typical (002) reflection of graphitic carbon. Fig. S5b (ESI $\dagger$ ) shows the size of Ni NPs at each temperature, estimated by applying the Debye-Scherrer equation to the (111) reflection. Below $600{ }^{\circ} \mathrm{C}$, the sizes of the Ni NPs were less than $5 \mathrm{~nm}$. However, above $700{ }^{\circ} \mathrm{C}$, some of the small nanoparticles began to agglomerate to form larger Ni NPs (plotted as red and blue dots, respectively), as derived from the Debye-Scherrer equation with two deconvoluted peaks of the (111) reflection. Subsequently, when the temperature reached $900{ }^{\circ} \mathrm{C}$, the small Ni NPs ceased to agglomerate and resulted in a single data point of $\sim 35 \mathrm{~nm}$ sized Ni NPs. The number of expected peaks for deconvolution was determined from TEM images obtained at each temperature (Fig. S6, ESI $\dagger$ ). Since the solids heated to less than $300{ }^{\circ} \mathrm{C}$ were unstable under the e-beam during TEM analysis, images were obtained for samples treated at 400, 500, 600, 700, 800, 900 , and $1000{ }^{\circ} \mathrm{C}$. Similar to the XRPD results, when the temperature was $400{ }^{\circ} \mathrm{C}$, Ni NPs embedded in the carbon matrix were formed. As the temperature increased, the shapes of the Ni NPs became more regular and crystalline, and had diameters of less than $5 \mathrm{~nm}$. Meanwhile, owing to the catalytic function of Ni NPs, the organic species from the EDTA began to decompose and subsequently formed $\mathrm{sp}^{2}$ carbons on the Ni NPs. A similar phenomenon has been observed with the growth of CNTs assisted by $\mathrm{Ni}$ catalysts. ${ }^{16}$ In the present system where the $\mathrm{Ni}$ NPs were embedded within carbon layers, the total directional 
(a)

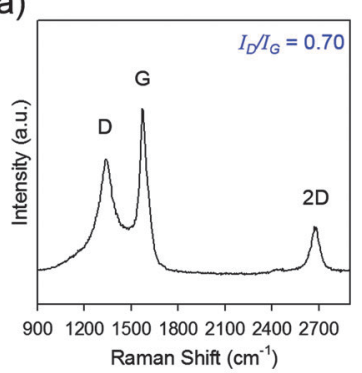

(b)

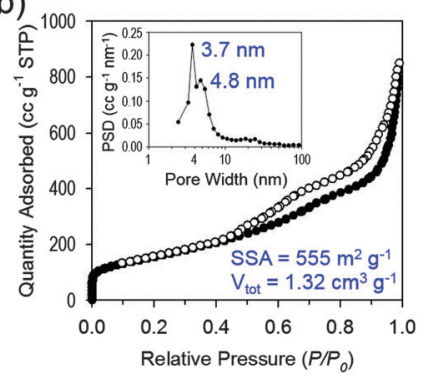

Fig. 2 Structural and electronic characterization of 3D mesoG. (a) Raman spectrum. (b) $\mathrm{N}_{2}$ adsorption-desorption isotherm and the corresponding $\mathrm{BJH}$ pore size distribution curve (inset).

contact of carbon with Ni NP surfaces results in spherical shells rather than tubular structures. Therefore, the size of the Ni NPs formed in situ dictates the inner diameter of the hollow carbon. In the TEM image of the solid treated at $700{ }^{\circ} \mathrm{C}$ (Fig. S6, ESI $\dagger$ ), Ni NPs with diameters larger than $50 \mathrm{~nm}$ were observed in the presence of small Ni NPs with diameters of $c a .5 \mathrm{~nm}$. We presume that this was due to the secondary agglomeration of the $4 \mathrm{~nm}$ Ni NPs that was initiated upon heating at the temperatures above $\sim 600{ }^{\circ} \mathrm{C}$. The mobility of the Ni NPs can be explained by the melting-point depression in nanoscale materials. ${ }^{17}$ While the melting temperature of bulk Ni metal is $1453{ }^{\circ} \mathrm{C}$, metal particles smaller than $\sim 100 \mathrm{~nm}$ can melt at significantly lower temperatures; indeed, the melting point of $4 \mathrm{~nm} \mathrm{Ni}$ metal particles was calculated to be $\sim 700{ }^{\circ} \mathrm{C}$, a temperature at which the Ni NPs began to agglomerate. Therefore, after heating at $1000{ }^{\circ} \mathrm{C}$ for $1 \mathrm{~h}$, the $3 \mathrm{D}$ mesoG coexisted with large Ni NPs. Likewise, the surfaces of the large Ni NPs also act as catalysts to generate large carbon shells, as shown in Fig. S6 (ESI†).

To explore the structural and electronic properties of the 3D mesoG material, Raman spectroscopy was conducted (Fig. 2a). A broad D-band attributed to the disorder-induced mode and a relatively sharp G-band attributed to the $\mathrm{E}_{2 \mathrm{~g}}$-mode from the $\mathrm{sp}^{2}$ carbon domain appeared at 1340 and $1575 \mathrm{~cm}^{-1}$, respectively, along with the $2 \mathrm{D}$-band at $2676 \mathrm{~cm}^{-1}$. The G-peak indicated the presence of crystalline graphitic carbon in the $3 \mathrm{D}$ mesoG. The ratio between the intensity of the D- and G-bands $\left(I_{\mathrm{D}} / I_{\mathrm{G}}\right)$, which is commonly used as an indicator for the degree of disorder in graphitic materials, was 0.70 . This $I_{\mathrm{D}} / I_{\mathrm{G}}$ ratio was comparable to or smaller than those measured for $\mathrm{GO}$ and $\mathrm{rGO}\left(I_{\mathrm{D}} / I_{\mathrm{G}}=\sim 1\right)^{18}$ as well as CVD-grown multi-wall CNTs $\left(I_{\mathrm{D}} / I_{\mathrm{G}}=0.7-1.3\right),{ }^{19}$ thus indicating that high quality $3 \mathrm{D}$ mesoG was formed (Table S2, ESI $\dagger$ ). The broad D-peak might originate from the distorted nature of the hexagonal $\mathrm{sp}^{2}$ carbons because of significant lattice stress arising from high curvature of the $4 \mathrm{~nm}$ hollow graphene shell in 3D mesoG. As listed in Table S1 (ESI $\dagger$ ), elemental analysis of 3D mesoG revealed a high $\mathrm{C} / \mathrm{O}$ ratio of 55 , which was higher than that of some forms of chemically or thermally reduced graphene oxide $(\mathrm{rGO})(\sim 20) .{ }^{20}$ Regardless, such a high $\mathrm{C} / \mathrm{O}$ atomic ratio implies the presence of limited oxygen-containing functionalities, which may lead to improved physical properties. In order to assess the porous structure of 3D mesoG, nitrogen adsorption-desorption measurements were conducted. As shown in Fig. 3b, 3D mesoG exhibited typical type IV

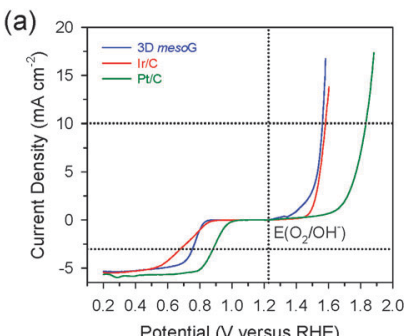

Potential ( $V$ versus RHE)
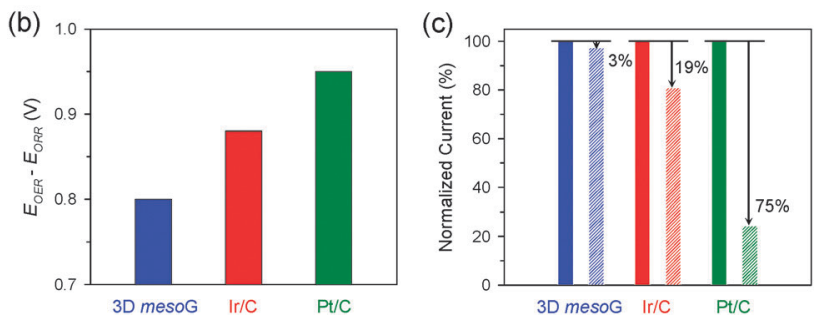

Fig. 3 Electrocatalytic activity and durability of 3D mesoG in the OER and ORR. (a) Polarization curves showing ORR and OER activities of 3D mesoG, $\mathrm{Ir} / \mathrm{C}$, and $\mathrm{Pt} / \mathrm{C}$ catalysts. (b) Bar graph showing the potential differences to drive $10 \mathrm{~mA} \mathrm{~cm}^{-2}$ for the OER and $-3 \mathrm{~mA} \mathrm{~cm}^{-2}$ for the ORR. (c) The changes in relative current densities of $3 \mathrm{D}$ mesoG, $\mathrm{Ir} / \mathrm{C}$, and $\mathrm{Pt} / \mathrm{C}$ catalysts for the OER before and after cycling tests.

isotherms with an $H 3$ type hysteresis loop over a relative pressure range of $0.42<P / P_{0}<0.99$, characteristic of a mesoporous material. The Barrett-Joyner-Halenda (BJH) pore size distribution curve (Fig. 2b, inset) indicated that the sizes of the mesopores were centered around $4 \mathrm{~nm}$, which was in good agreement with the TEM analysis. The highly porous nature of $3 \mathrm{D}$ mesoG gave rise to a relatively large Brunauer-Emmett-Teller (BET) specific surface area (SSA) of $555 \mathrm{~m}^{2} \mathrm{~g}^{-1}$, which was comparable to the specific surface area of five-layered graphene calculated from the theoretical SSA of monolayer graphene $\left(2630 \mathrm{~m}^{2} \mathrm{~g}^{-1}\right)$. In addition, $3 \mathrm{D}$ mesoG exhibited a very high total pore volume $\left(V_{\text {tot }}\right)$ of $1.32 \mathrm{~cm}^{3} \mathrm{~g}^{-1}$.

Overall, the characterization data were consistent with the material with large surface area from a readily-accessible Ni coordination complex. It is noteworthy that it was previously challenging to prepare 3D graphene with such small, monodisperse mesopores without the need for additional pore generation processes, such as the introduction and removal of various templates (e.g., $\mathrm{Ni}$ foams ${ }^{8}$ or silica beads $\left.{ }^{9}\right)$. Furthermore, the present method can proceed without the use of reductive gases (e.g., $\mathrm{H}_{2}$ ), which is typically required to form the carbons observed within the graphene layers. As such, this method represents a significant advancement in the preparation of 3D graphene materials in terms of simplicity of the synthetic process as well as the quality of the resulting materials.

To utilize the structural properties exhibited by 3D mesoG, we investigated its bifunctional electrocatalytic activity in ORR and OER, which are relevant for renewable energy technologies. ${ }^{14,21}$ The activities of Ir/C (20 wt\% Ir, Premetek) and Pt/C (20 wt\% Pt, Johnson-Matthey) were also evaluated as benchmarks. The polarization curves for the ORR and OER were measured in $0.1 \mathrm{M} \mathrm{KOH}$ at $1600 \mathrm{rpm}$ using the rotating disk electrode (RDE) technique (Fig. 3a). In the OER, the 3D mesoG material showed a high activity that was comparable to that of noble-metal-based Ir/C and was significantly higher than that of $\mathrm{Pt} / \mathrm{C}$. The potential 
to drive $10 \mathrm{~mA} \mathrm{~cm}{ }^{-2}$ for $3 \mathrm{D}$ mesoG was $1.56 \mathrm{~V}$ (vs. reversible hydrogen electrode (RHE), overpotential $(\eta)=330 \mathrm{mV}$ ), which was slightly better than that of $\operatorname{Ir} / \mathrm{C}(1.58 \mathrm{~V}, \eta=350 \mathrm{mV})$ and significantly better than that of $\mathrm{Pt} / \mathrm{C}(1.83 \mathrm{~V}, \eta=600 \mathrm{mV})$. In the ORR, 3D mesoG also showed high activity, which approached that of $\mathrm{Pt} / \mathrm{C}$ and exceeded that of the $\mathrm{Ir} / \mathrm{C}$ catalyst. The potentials required to reach $-3 \mathrm{~mA} \mathrm{~cm}^{-2}$ during the ORR were $0.76 \mathrm{~V}, 0.88 \mathrm{~V}$, and $0.70 \mathrm{~V}$ for 3D mesoG, Pt/C, and Ir/C, respectively. To quantitatively compare the bifunctional activity (oxygen electrode activity) of the catalysts for the OER and ORR, the potential difference to drive $10 \mathrm{~mA} \mathrm{~cm} \mathrm{~cm}^{-2}$ and $-3 \mathrm{~mA} \mathrm{~cm}{ }^{-2}$ (or the sum of overpotentials at those current densities) was calculated (Fig. 3b and Table S3, $\mathrm{ESI} \dagger){ }^{22}$ Remarkably, the 3D mesoG material exhibited the highest oxygen electrode activity among the catalysts compared: indeed, the potential difference of the $3 \mathrm{D}$ mesoG $(0.80 \mathrm{~V})$ was lower than that of the noble metal-based $\mathrm{Ir} / \mathrm{C}(0.88 \mathrm{~V})$ and $\mathrm{Pt} / \mathrm{C}(0.95 \mathrm{~V})$ catalysts. It should also be noted that the comparison of the oxygen electrode activities of the reported catalysts indicated that the 3D mesoG may be ideally suited for use as a carbon-based bifunctional catalyst for the ORR and OER (Table S4, ESI $\dagger$ ) and a promising catalyst for use in regenerative fuel cells as well as rechargeable metal-air batteries. The high bifunctional activity of 3D mesoG may originate from its very large surface area, with numerous defect sites due to the high curvature of its structure. In addition, the presence of nitrogen and nickel species in the carbon framework also contributed to the high catalytic activity. ${ }^{23}$

Finally, we assessed the structural stability of the 3D mesoG material via durability tests during the OER. Specifically, the 3D mesoG material as well as $\mathrm{Ir} / \mathrm{C}$ and $\mathrm{Pt} / \mathrm{C}$ catalysts were cycled from 1.20 to $1.70 \mathrm{~V} 100$ times (Fig. S7, ESI $\dagger$ ). A comparison of the current densities at $1.70 \mathrm{~V}$ before and after the cycling tests revealed that $3 \mathrm{D}$ mesoG underwent only a $3 \%$ decay in the current density, whereas the OER activities of Ir/C and Pt/C catalysts declined by $19 \%$ and 75\%, respectively (Fig. 3c). Carbon-supported metal nanoparticles are subject to various deactivation processes, such as carbon oxidation, metal dissolution, and Ostwald ripening, which are more pronounced at high oxidative OER potentials $(>1.4 \mathrm{~V})$. The superior stability of the 3D mesoG material can be attributed to the highly graphitic carbon framework, which appears in the aforementioned experiments to be more resistant to oxidation than the amorphous carbon in $\mathrm{Ir} / \mathrm{C}$ and $\mathrm{Pt} / \mathrm{C}$.

In conclusion, we describe a straightforward and cost-effective method to synthesize 3D mesoporous graphene frameworks from a $\mathrm{Ni}(\mathrm{II})$ molecular coordination compound. The resulting 3D mesoG was composed of 3D interconnected hollow $\mathrm{N}$-doped graphene shells consisting of 3-4 layers with small, uniform mesopores of $c a .4 \mathrm{~nm}$. The 3D mesoG material exhibited high bifunctional electrocatalytic activity and durability in the ORR and OER, which in our case was found to be superior to that of noble metal catalysts such as Pt/C and Ir/C. Similar to recent studies regarding the conversion of metalorganic frameworks, ${ }^{24}$ we believe that the method described herein can be extended to a variety of porous graphene frameworks, including heteroatom-doped graphene, and utilized as a high-performance material for use in energy conversion and storage applications. Furthermore, we envisage that the conversion of small molecular metal complexes into nanostructured materials can be exploited for the preparation of novel functional materials.
This work was supported by the Basic Science Research Program through the National Research Foundation (NRF) of Korea (NRF-2013R1A1A3010846; NRF-2014M1A8A1049255; NRF2013R1A1A2012960) as well as the IBS (IBS-R019-D1 to CWB).

\section{Notes and references}

1 H. Y. Yang, Z. J. Han, S. F. Yu, K. L. Pey, K. Ostrikov and R. Karnik, Nat. Commun., 2013, 4, 2220.

2 (a) X. Ji, K. T. Lee and L. F. Nazar, Nat. Mater., 2009, 8, 500; (b) C. Merlet, B. Rotenberg, P. A. Madden, P.-L. Taberna, P. Simon, Y. Gogotsi and M. Salanner, Nat. Mater., 2012, 11, 306; (c) Y. Zhu, S. Murali, M. D. Stoller, K. J. Ganesh, W. Cai, P. J. Ferreira, A. Pirkle, R. M. Wallace, K. A. Cychosz, M. Thommes, D. Su, E. A. Stach and R. S. Ruoff, Science, 2011, 332, 1537.

3 (a) C. Su and K. P. Loh, Acc. Chem. Res., 2013, 46, 2275; (b) D. S. Su, S. Perathoner and G. Centi, Chem. Rev., 2013, 113, 5782; (c) S. Navalon, A. Dhakshinamoorthy, M. Alvaro and H. Garcia, Chem. Rev., 2014, 114, 6179.

4 Y. Zhu, S. Murali, W. Cai, X. Li, J. W. Suk, J. R. Potts and R. S. Ruoff, Adv. Mater., 2010, 22, 3906.

5 K. S. Kim, Y. Zhao, H. Jang, S. Y. Lee, J. M. Kim, K. S. Kim, J.-H. Ahn, P. Kim, J.-Y. Choi and B. H. Hong, Nature, 2009, 457, 706.

6 A. A. Balandin, S. Ghosh, W. Bao, I. Calizo, D. Teweldebrhan, F. Miao and C. N. Lau, Nano Lett., 2008, 8, 902.

7 M. J. Allen, V. C. Tung and R. B. Kaner, Chem. Rev., 2010, 110, 132.

8 Z. Chen, W. Ren, L. Gao, B. Liu, S. Pei and H.-M. Cheng, Nat. Mater., 2011, 10, 424.

9 J.-C. Yoon, J.-S. Lee, S.-I. Kim, K.-H. Kim and J.-H. Jang, Sci. Rep., 2013, 3, 1788.

10 C. Cui, W. Qian, Y. Yu, C. Kong, B. Yu, L. Xiang and F. Wei, J. Am. Chem. Soc., 2014, 136, 2256.

11 (a) Z.-S. Wu, Y. Sun, Y.-Z. Tan, S. Yang, X. Feng and K. Müllen, J. Am. Chem. Soc., 2012, 134, 19532; (b) L. Zhang, F. Zhang, X. Yang, G. Long, Y. Wu, T. Zhang, K. Leng, Y. Huang, Y. Ma, A. Yu and Y. Chen, Sci. Rep., 2013, 3, 1408; (c) C. Wu, X. Huang, G. Wang, L. Lv, G. Chen, G. Li and P. Jiang, Adv. Funct. Mater., 2013, 23, 506.

12 (a) K. H. Kim, M. H. Yang, K. M. Cho, Y.-S. Jun, S. B. Lee and H.-T. Jung, Sci. Rep., 2013, 3, 3251; (b) Z. Fan, J. Yan, L. Zhi, Q. Zhang, T. Wei, J. Feng, M. Zhang, W. Qian and F. Wei, Adv. Mater., 2010, 22, 3723; (c) J. W. Burress, S. Gadipelli, J. Ford, J. M. Simmons, W. Zhou and T. Yildirim, Angew. Chem., Int. Ed., 2010, 49, 8902.

13 T. K. Kim, J. Y. Cheon, K. Yoo, J. W. Kim, S. Hyun, H. S. Shin, S. H. Joo and H. R. Moon, J. Mater. Chem. A, 2013, 1, 8432.

14 (a) S. Park, Y. Shao, J. Liu and Y. Wang, Energy Environ. Sci., 2012, 5, 9331; (b) P. G. Bruce, S. A. Freunberger, L. J. Hardwick and J.-M. Tarascon, Nat. Mater., 2012, 11, 19.

15 E. Coronado, M. Drillon, A. Fuertes, D. Beltran, A. Mosset and J. Galy, J. Am. Chem. Soc., 1986, 108, 900.

16 M. Kumar, Carbon Nanotubes - Synthesis, Characterization, Applications, in Carbon Nanotube Synthesis and Growth Mechanism [Online], ed. S. Yellampalli, InTech, 2011, ch. 8, http://www.intechopen.com/ books/carbon-nanotubes-synthesis-characterization-applications/carbonnanotube-synthesis-and-growth-mechanism, accessed February 5, 2015.

17 M. Anna, G. N. Albert and I. K. Esko, J. Phys.: Condens. Matter, 2013, 15, S3011.

18 V. Georgakilas, M. Otyepka, A. B. Bourlinos, V. Chandra, N. Kim, K. C. Kemp, P. Hobza, R. Zboril and K. S. Kim, Chem. Rev., 2012, 112, 6156.

19 (a) M. Sveningsson, R.-E. Morjan, O. A. Nerushev, Y. Sato, J. Bäckström, E. E. B. Campbell and F. Rohmund, Appl. Phys. A: Mater. Sci. Process., 2001, 73, 409; (b) K. Kwok and W. K. S. Chiu, Carbon, 2005, 43, 437; (c) W. Li, H. Zhang, C. Wang, Y. Zhang, L. Xu, K. Zhu and S. Xie, Appl. Phys. Lett., 1997, 70, 2684.

20 C. K. Chun and M. Pumera, Chem. Soc. Rev., 2014, 43, 291.

21 R. Cao, J.-S. Lee, M. Liu and J. Cho, Adv. Energy Mater., 2012, 2, 816. 22 Y. Gorlin and T. F. Jaramillo, J. Am. Chem. Soc., 2010, 132, 13612.

23 Y. Zhao, R. Nakamura, K. Kamiya, S. Nakanishi and K. Hashimoto, Nat. Commun., 2013, 4, 2390.

24 (a) T. K. Kim, K. J. Lee, J. Y. Cheon, J. H. Lee, S. H. Joo and H. R. Moon, J. Am. Chem. Soc., 2013, 135, 8940; (b) J. H. Lee, Y. J. Sa, T. K. Kim, H. R. Moon and S. H. Joo, J. Mater. Chem. A, 2014, 2, 10435; (c) K. J. Lee, T.-H. Kim, T. K. Kim, J. H. Lee, H.-K. Song and H. R. Moon, J. Mater. Chem. A, 2014, 2, 14393. 